\title{
Water-Preserving and Salt-Resistant Slow-Release Fertilizers of Polyacrylic Acid-Potassium Humate Coated Ammonium Dihydrogen Phosphate
}

\author{
Hongping Li ${ }^{1,2,+}$, Lanwen Yang ${ }^{1,2}$, Jianxin Cao ${ }^{1,2,+}$, Chenchen Nie ${ }^{1,2}$, Hao Liu ${ }^{1,2}$, Juan Tian ${ }^{3}$, Wenxing Chen ${ }^{3}$, \\ Pinglan Geng ${ }^{4}$ and Guiming Xie ${ }^{1,2, * \mathbb{D}}$ \\ 1 School of Chemistry and Chemical Engineering, Guizhou University, Guiyang 550025, China; \\ hongpli547@163.com (H.L.); lanwen958@126.com (L.Y.); jxcao@gzu.edu.cn (J.C.); \\ ncc15139056557@163.com (C.N.); haoliu2019liu@163.com (H.L.) \\ 2 Key Laboratory of Guizhou Province for Green Chemical Industry and Clean Energy Technology, \\ Guizhou University, Guiyang 550025, China \\ 3 Guizhou Research Institute of Chemical Industry, Guiyang 550002, China; rtr1204@126.com (J.T.); \\ vincene@126.com (W.C.) \\ 4 Guizhou Institute of Products Quality Inspection \& Testing, Guiyang 550002, China; \\ Gengpinglan717@163.com \\ * Correspondence: gmxie@gzu.edu.cn \\ + H.L. and J.C. equally contributed to this study.
}

check for updates

Citation: Li, H.; Yang, L.; Cao, J.; Nie, C.; Liu, H.; Tian, J.; Chen, W.; Geng, P.; Xie, G. Water-Preserving and Salt-Resistant Slow-Release Fertilizers of Polyacrylic Acid-Potassium Humate Coated Ammonium Dihydrogen Phosphate. Polymers 2021, 13, 2844. https://doi.org/ $10.3390 /$ polym 13172844

Academic Editor: Marta Otero

Received: 16 May 2021

Accepted: 17 August 2021

Published: 24 August 2021

Publisher's Note: MDPI stays neutral with regard to jurisdictional claims in published maps and institutional affiliations.

Copyright: () 2021 by the authors Licensee MDPI, Basel, Switzerland. This article is an open access article distributed under the terms and conditions of the Creative Commons Attribution (CC BY) license (https:// creativecommons.org/licenses/by/ $4.0 /)$.
Abstract: Polyacrylic acid (PAA) has high water absorbency but poor salt resistance. Humic acid (HA) extracted from lignite was introduced into the cross-linked copolymer systems of AA to improve the water absorbency and salt-tolerance. A polyacrylic acid-potassium humate (PAA-KHA) coated ammonium dihydrogen phosphate (ADP) fertilizer with water-preserving, salt-resistant and slow-release properties was prepared. The main properties of HA extracted from lignite oxidized by $\mathrm{H}_{2} \mathrm{O}_{2}$ were studied. Furthermore, the synthesis process, water absorbency of PAA-KHA in deionized water and in $\mathrm{NaCl}$ solution, morphologies of PAA-KHA, and the slow-release performance of the fertilizer (ADP@PAA-KHA) were investigated. The results showed PAA-KHA had a layered interpenetrating network, which can provide sufficient storage space for water and nutrients. The salty water absorbency of PAA-KHA increased by about 3 times compared to PAA. Both the $\mathrm{PO}_{4}{ }^{3-}$ and $\mathrm{NH}_{4}{ }^{+}$cumulative release of ADP@PAA-KHA with a coating rate of $10 \%$ in deionized water, were less than $20 \%$ within $24 \mathrm{~h}$, and were $55.71 \%$ and $28.04 \%$ after the 15 th day, respectively. The weight change of ADP@PAA-KHA before and after absorbing water was about 53 times in deionized water and about 4 times in $1 \mathrm{wt} \%$ of $\mathrm{NaCl}$ salty water. The results show that ADP@PAA-KHA has excellent properties of water retention, salt resistance and slow-release. This will efficiently improve the utilization of fertilizer and reduce the irrigation water consumption at the same time.

Keywords: polyacrylic acid-potassium humate; water retention; salt resistance; ammonium dihydrogen phosphate; slow-release fertilizer

\section{Introduction}

Chemical fertilizers became a useful method to increase grain production to meet the food needs of the rapidly growing global population. However, the direct application of chemical fertilizer causes the loss of fertilizer nutrients due to volatilization of nitrogen in the forms of $\mathrm{NH}_{3}$ and nitrous oxides, and leaching in the soil, leading to the rising cost of food production and environmental pollution [1]. Furthermore, water resources become increasingly scarce with global warming, and the dry land without irrigation, such as arid and semi-arid land, accounts for a high proportion of the total arable land [2], Therefore, agricultural development must take the course of sustainable development of water saving, 
fertilizer reduction and pollution control. Amazingly, the water-preserving and slowrelease fertilizer not only makes the release of nutrients match requirements of crops at every stage of growth and development, but also can improve fertilizing, use efficiency to reduce irrigation water consumption and the risk of environmental pollution [3].

Superabsorbent polymers (SAPs) are conducive to use as the coated materials to produce the water-preserving and slow-release fertilizer because the high-water absorbency and the ability to sustain the absorbed water under long time pressure [1]. Furthermore, advantages of SAPs coating materials include improving soil, reducing soil degradation, limiting the evaporation loss, alleviating environmental pollution, lowering crop mortality rates, and enhancing the retention period of plant nutrients in the soil [4]. On the industrial scale of SAPs, acrylic acid (AA) and acrylamide (AM) are the major and common monomers widely employed by copolymerization [5-7]. Polyacrylic acid (PAA) and polyacrylamide (PAM) are considered the most widely used water retention agents because of superior water absorbency in water (about $300-500 \mathrm{~g} \cdot \mathrm{g}^{-1}$ ) and water retention capacity in synthetic polymers [8]. Nevertheless, the effectiveness of PAA and PAM is hampered by low salt resistance (less than $100 \mathrm{~g} \cdot \mathrm{g}^{-1}$ in $0.9 \mathrm{wt} \%$ of $\mathrm{NaCl}$ solution) due to its single type of hydrophilic group [9], low gel strength after water absorption [10], and poor biodegradation [8]. Therefore, of interest are effective approaches to improve their salt-tolerance, mechanical properties, and degradability, such as introduction of kaolin and bentonite to enhance mechanical performance of PAA or PAM polymers $[7,11]$. The nature polymers can be introduced into the cross-linked copolymer systems of AA or AM [8], such as cellulose [12], natural rubber [13], starch [14,15] and chitosan [16], to improve the degradability, biocompatibility and environmental friendliness. However, SAPs based on natural polymers, such as cellulose, starch and chitosan, are prone to degradation resulting in a short cycle of nutrient release and relatively low slow-release performance [17], and suffer from low water absorption rate, thus have to be used in larger amounts. In addition, most of them are composed of multiple (more than three) substances [18-21], which complicates the preparation processes and increases their cost.

Humic acid (HA) is an organic carrier and synergist of plant nutrition, which plays a positive role in plant growth [22]. At the same time, HA is a kind of environment-friendly substance with abundant source, low price, safety and non-toxicity [23]. HA is composed of aromatic rings, bridges (including alkylene, ether or ester linkages) and side chains (including alkyl, carboxyl and hydroxyl groups) [24], and it has high chemical reactivity in soil, such as ion exchange, complexation and oxidation-reduction, due to its various active groups and large specific surface area [25], thus it can be introduced into the SAPs to improve water absorbency and salt resistance of the polymer to enhance the water retention capacity and chemical properties of the soil, such as its ability to adsorb soluble salts in the soil, hinder harmful cations, reduce soil salt concentration and so on [26]. Furthermore, Shen et al. [27] showed that bentonite was modified by introducing HA into the interlayer space of bentonite, which exhibited a much higher adsorption capacity to $\mathrm{NH}_{4}{ }^{+}-\mathrm{N}$ and $\mathrm{NO}_{3}{ }^{-}-\mathrm{N}$ in soil. Previous research in our group also showed that HA has strong adsorption on $\mathrm{PO}_{4}{ }^{3-}$ and $\mathrm{NH}_{4}{ }^{+}$[28]. Therefore, introduction of the HA in the SAPs as coating materials not only can effectively improve the performance of water absorbency and salt resistance, but also can promote the absorption of nutrients by plants.

Lignite is rich in resources [29], cheap in price, and has a high content of HA organic matter. On the basis of the above background and our previous studies [28], in this paper, the HA was extracted from lignite with $\mathrm{H}_{2} \mathrm{O}_{2}$ as an oxygenation agent. Then a coating material with high water absorbability and salt resistance was obtained by the aqueous solution polymerization of acrylic acid and potassium humate. The effects of synthetic conditions on the water absorbency and salty water absorbency of coating materials and the sustained-release performance of coated ammonium dihydrogen phosphate fertilizer were investigated. 


\section{Materials and Methods}

\subsection{Materials}

Lignite was obtained from Anshun of Guizhou province, China. Acrylic acid (AA), ammonium persulfate (APS), and soluble starch were purchased from Tianjin Kemiou Chemical Reagent Co., Ltd., Tianjin, China; hydrogen peroxide solution $\left(\mathrm{H}_{2} \mathrm{O}_{2}, 30 \mathrm{wt} \%\right)$, potassium hydroxide $(\mathrm{KOH})$, calcium acetate, barium hydroxide $\left(\mathrm{Ba}(\mathrm{OH})_{2}\right)$, sodium chloride $(\mathrm{NaCl})$, sodium hydroxide $(\mathrm{NaOH})$, ammonium dihydrogen phosphate (ADP) were purchased from Chengdu Jinshan Chemical Reagent Co., Ltd., Chengdu, China; N, N'methylene amide (MBA) was purchased from Shanghai Yuanye Biotechnology Co., Ltd., Shanghai, China; phenolphthalein, sodium pyrophosphate and ammonium ferrous sulfate were purchased from Tianjin Zhiyuan Chemical Reagent Co., Ltd., Tianjin, China; potassium dichromate (premium pure) was from Beijing Balinwei Technology Co., Ltd., Beijing, China; 1,10-Phenanthroline monohydrate was purchased from Shanghai Ika Biotechnology Co., Ltd., Shanghai, China; Sulfuric acid $\left(\mathrm{H}_{2} \mathrm{SO}_{4}, 95-98 \mathrm{wt} \%\right)$ and hydrochloric acid $(\mathrm{HCl}$, 36-38 wt\%) were purchased from Chongqing Chuandong Chemical (Group) Co., Ltd., Chongqing, China. All the above chemicals were of analytical grade unless otherwise stated. Deionized water was used in all the experiments.

\subsection{Methods}

\subsubsection{Extraction of $\mathrm{HA}$ from Lignite by $\mathrm{H}_{2} \mathrm{O}_{2}$ Oxygenation}

Lignite was dried and ground to a particle size of less than $0.2 \mathrm{~mm}$, and then $10 \mathrm{~g}$ were placed in a $250 \mathrm{~mL}$ of beaker; meanwhile, $10 \mathrm{~mL}$ of $\mathrm{H}_{2} \mathrm{O}_{2}$ solution was added, and then stirred at $200 \mathrm{rpm}$ for $24 \mathrm{~h}$ in the dark at room temperature. After that, oxygenated lignite was obtained by filtering, and drying at $50^{\circ} \mathrm{C}$.

An amount of $5 \mathrm{~g}$ of oxygenated lignite was added in $50 \mathrm{~mL} 2 \mathrm{wt} \%$ of $\mathrm{KOH}$ solution and then reacted at $400 \mathrm{rpm}$ and $70^{\circ} \mathrm{C}$ for $30 \mathrm{~min}$ in a three-neck flask. Then the supernatant of the mixture was divided into two parts after separating by the centrifugation. One of the supernatants was blown dry at $60^{\circ} \mathrm{C}$ to obtain potassium humate (KHA). The other supernatant had $0.2 \mathrm{~mol} \cdot \mathrm{L}^{-1}$ of $\mathrm{HCl}$ solution added to adjust the $\mathrm{pH}$ to 1.5 and stood for $24 \mathrm{~h}$. Thereafter, the sediment obtained by filtration was washed with deionized water until neutral and was dried at $60^{\circ} \mathrm{C}$ to acquire HA.

\subsubsection{Preparation of PAA-KHA}

The typical polymerization process was as follows: $5 \mathrm{~mL}$ of deionized water and $2 \mathrm{~g}$ of AA monomer (neutralized to $50 \%$ degree of neutralization by $0.02 \mathrm{~g} \cdot \mathrm{mL}^{-1}$ of $\mathrm{KOH}$ solution beforehand) were added to a three-neck flask, equipped with a thermometer, a nitrogen line and a reflux condenser. Then $6 \mathrm{wt} \%$ of KHA, $2.1 \mathrm{wt} \%$ of APS and $0.2 \mathrm{wt} \%$ of MBA (based on the AA monomer, respectively) were added under stirring of $500 \mathrm{rpm}$. Nitrogen was continuously filled in to remove the air, and then the mixture in the flask was kept in a $70{ }^{\circ} \mathrm{C}$ water bath for $4.5 \mathrm{~h}$. The reaction was terminated by cooling to room temperature, and a polymer solution with a certain fluidity was obtained, which was directly used as a coating material to prepare slow-release fertilizer. Additionally, the polymer solution was washed, precipitated, and separated by ethanol, then it was dried in an oven at $60^{\circ} \mathrm{C}$, which was used for analysis and characterization.

PAA material was prepared under the same conditions as PAA-KHA except that it did not add the $6 \mathrm{wt} \%$ of KHA.

\subsubsection{Preparation of ADP@PAA-KHA}

Previous research showed that oxygenated lignite has strong adsorption on $\mathrm{PO}_{4}{ }^{3-}$ and $\mathrm{NH}_{4}{ }^{+}$[28], which is of benefit to the absorption of crops. Therefore, soluble starch was selected as the binder and granulated with the oxygenated lignite and ADP to prepare fertilizer cores. The specific preparation process was as follows: $1000 \mathrm{~g}$ mixture of oxygenated lignite, ADP and soluble starch with the mass ratio of 4:2:2 was granulated in a rotary granulator (BYC -300 , Shanghai Tianhe Machinery Co. Ltd., Shanghai, China) at 
$30 \mathrm{rpm}$ for $30 \mathrm{~min}$ under the condition of intermittent spraying a small amount of water, and then the fertilizer cores were obtained by air-drying, and they were screened. Then $500 \mathrm{~g}$ of fertilizer cores were placed again in the rotary granulator and slowly poured into $50 \mathrm{~g}$ of PAA-KHA polymer solution at the rotation speed of $35 \mathrm{rpm}$ and kept for $30 \mathrm{~min}$ at $60{ }^{\circ} \mathrm{C}$ to obtain the ADP@PAA-KHA fertilizers. The coated rate $(\mathrm{w} \%)$ was calculated according to the Formula (1).

$$
\mathrm{w} \%=\frac{\mathrm{m}_{2}-\mathrm{m}_{1}}{\mathrm{~m}_{1}} \times 100 \%
$$

where $\mathrm{m}_{1}(\mathrm{~g})$ and $\mathrm{m}_{2}(\mathrm{~g})$ was the weight of fertilizer cores and ADP@PAA-KHA, respectively.

\subsection{Characterization}

\subsubsection{Determination the Properties of HA}

Determination of HA ad (\%) in oxygenated lignite was done according to ISO 5073: 1999. The content of the carboxyl groups and total acid groups were determined by calcium acetate titration and barium hydroxide titration respectively, and the content of phenolic hydroxyl groups were the content of the total acid groups minus carboxyl groups [30]. All the titration experiments were conducted over three parallel experiments, and the final experimental results were the average value of the three experiments.

\subsubsection{Determination of Water Absorbency of PAA-KHA in Deionized Water and Salty Water}

PAA-KHA with mass of $\mathrm{M}_{1}$ was accurately weighed and put into a beaker with $1000 \mathrm{~mL}$ of deionized water (or $1 \mathrm{wt} \%$ of $\mathrm{NaCl}$ salty water solution) and underwent full swelling at $25^{\circ} \mathrm{C}$ for $24 \mathrm{~h}$. The swollen material was filtered out with a sieve until there was no water dripping and it reached a weight of $\mathrm{M}_{2}$. Then the water absorbency of PAAKHA in deionized and salty water was calculated according to Formula (2). The water absorbency of PAA in deionized water and salty water was tested by the same method as the PAA-KHA. All the experiments were conducted across three parallel experiments, and the final experimental results were the average value of the three experiments.

$$
\mathrm{H}\left(\mathrm{g} \cdot \mathrm{g}^{-1}\right)=\left(\mathrm{M}_{2}-\mathrm{M}_{1}\right) / \mathrm{M}_{1}
$$

where $\mathrm{H}\left(\mathrm{g} \cdot \mathrm{g}^{-1}\right)$ was the water absorbency of PAA-KHA in deionized or salty water, $\mathrm{M}_{1}$ (g) was the mass of PAA-KHA, and $\mathrm{M}_{2}$ (g) was the mass of PAA-KHA after fully swelling in deionized or salty water, respectively.

To analyze the repeated water absorbency of PAA-KHA, the test procedures were as follows: the PAA-KHA was fully swelled in deionized water and its water absorbency was calculated as above. Then the PAA-KHA was dried to a constant weight at $30^{\circ} \mathrm{C}$ and put back into the deionized water to fully swell to test the water absorbency again. The procedures were repeated five times. The repeated water absorbency of PAA was tested by the same method as that of the PAA-KHA. A certain amount of PAA-KHA (or PAA) was weighed at $25^{\circ} \mathrm{C}$, placed in water until fully swelled, and then transferred into an incubator at $35^{\circ} \mathrm{C}$. The mass of PAA-KHA (or PAA) was weighed at specific intervals and its water loss was calculated to determine the water retention capacity of PAA-KHA (or PAA). All experiments were conducted in parallel, and the final results were averaged.

\subsubsection{Determination of Slow-Release Performance of the ADP@PAA-KHA Fertilizer}

The static water immersion method was selected to determine the cumulative release rate of each nutrient element of ADP@PAA-KHA. A certain amount of ADP@PAA-KHA was placed in $500 \mathrm{~mL}$ of boiled deionized water in an incubator with a constant temperature of $25^{\circ} \mathrm{C}$. Liquid samples, weighed out at $10 \mathrm{~mL}$ at regular intervals, were used to determine the content of nutrient elements, and at the same time another $10 \mathrm{~mL}$ of boiled deionized water was replenished to the system. The concentrations of $\mathrm{NH}_{4}{ }^{+}$and $\mathrm{PO}_{4}{ }^{3-}$ 
were measured by American ion chromatograph (ICS-900, Dionex Company, Sunnyvale, CA, USA), and the cumulative release rate of each nutrient (W) was calculated according to the following Formula (3) [31].

$$
\mathrm{W}(\%)=\frac{\mathrm{V}_{\mathrm{E}} \sum_{1}^{\mathrm{n}-1} \mathrm{C}_{\mathrm{i}}+\mathrm{V}_{0} \mathrm{C}_{\mathrm{n}}}{\mathrm{m}_{\mathrm{x}}} \times 100 \%
$$

where $\mathrm{W}(\%)$ was the cumulative release rate of each nutrient, $\mathrm{V}_{\mathrm{E}}(\mathrm{L})$ and $\mathrm{V}_{0}(\mathrm{~L})$ were the volume of sample solution and solution in container, respectively, $\mathrm{C}_{\mathrm{i}}\left(\mathrm{mg} \cdot \mathrm{L}^{-1}\right)$ was the concentration of nutrient in the sample solution, $C_{n}\left(\mathrm{mg} \cdot \mathrm{L}^{-1}\right)$ was the concentration of the solution in the container, $\mathrm{n}$ and $\mathrm{i}$ were the number of samples, respectively and $\mathrm{m}_{\mathrm{x}}(\mathrm{mg})$ was the nutrient mass in the sample.

An FTIR spectrometer (Nicolet IS50, Thermo Fisher Scientific Company, Waltham, MA, USA) was used to analyze the surface functional groups of lignite, oxygenated lignite by $\mathrm{H}_{2} \mathrm{O}_{2}$, HA extracted from lignite and PAA-KHA [24,32].

Morphologies of PAA-KHA before and after water-absorption were observed using a scanning electron microscope (S-3400N, Hitachi, Japan). The samples were coated with a layer of gold before the microscopic examination. Energy dispersive spectroscopy (EDS, EDAX Octane Prime, Mahwah, NJ, USA) was used to analyze the element composition of the designated region of PAA-KHA. The swollen samples were freeze-dried in a freeze dryer (NAI-T1-5, NAI Precision Instrument Co., Ltd., Shanghai, China) at $-50{ }^{\circ} \mathrm{C}$ for $48 \mathrm{~h}$ before the test.

\section{Results and Discussion}

\subsection{Extraction of HA from Lignite}

As shown in Table 1 , after lignite oxygenation by $\mathrm{H}_{2} \mathrm{O}_{2}$, the total acid groups' content of lignite increased from 4.63 to $10.63 \mathrm{mmol} \cdot \mathrm{g}^{-1}$, while the carboxyl groups content increased from 2.35 to $3.20 \mathrm{mmol} \cdot \mathrm{g}^{-1}$. In addition, the phenolic hydroxyl groups' content increased from 2.28 to $7.60 \mathrm{mmol} \cdot \mathrm{g}^{-1}$ and the HA content increased from $18.78 \%$ to $35.13 \%$, a significant increase of $16.35 \%$. The results showed that $\mathrm{H}_{2} \mathrm{O}_{2}$ was as an outstanding oxidant of lignite, which significantly increased the HA production from lignite. The chemical structure differences of lignite, oxygenated lignite and HA are characterized by FTIR in Figure 1; the broadband at around $3400 \mathrm{~cm}^{-1}$ belongs to the stretching vibration of the $-\mathrm{OH}$ groups, and the broadband at around $3150 \mathrm{~cm}^{-1}$ belongs to the $\mathrm{N}-\mathrm{H}$ or $=\mathrm{C}-\mathrm{H}$ of the aromatic ring. The peaks occurring at about $2940-2920$ and $2850 \mathrm{~cm}^{-1}$ are attributed to the asymmetric and symmetric aliphatic $\mathrm{C}-\mathrm{H}$ stretching of $\mathrm{CH}_{2}$ groups. An intense peak at $1725-1710 \mathrm{~cm}^{-1}$ is attributed to $\mathrm{C}=\mathrm{O}$ stretching of $\mathrm{COOH}$. The peaks at $1600 \mathrm{~cm}^{-1}$ corresponded to the stretching vibration of $\mathrm{C}=\mathrm{C}$ in the aromatic nucleus. A peak at around $1380 \mathrm{~cm}^{-1}$ can be attributed to $\mathrm{C}-\mathrm{H}$ deformation of $\mathrm{CH}_{2}$ and $\mathrm{CH}_{3}$ groups and / or to antisymmetric stretching of COO- groups [24,32-34] These results showed that a variety of functional groups existed on HA and they were well-preserved after being oxidized by $\mathrm{H}_{2} \mathrm{O}_{2}$, which indicates that $\mathrm{H}_{2} \mathrm{O}_{2}$ is a suitable oxygenation agent for lignite.

Table 1. The characteristics of lignite and oxygenated lignite.

\begin{tabular}{ccc}
\hline Content & Lignite & Oxygenated Lignite \\
\hline Total acid groups $\left(\mathrm{mmol} \cdot \mathrm{g}^{-1}\right)$ & 4.63 & 10.63 \\
Carboxyl $\left(\mathrm{mmol} \cdot \mathrm{g}^{-1}\right)$ & 2.35 & 3.20 \\
Phenolic hydroxyl $\left(\mathrm{mmol} \cdot \mathrm{g}^{-1}\right)$ & 2.28 & 7.60 \\
HA ad $(\%)$ & 18.78 & 35.13 \\
\hline
\end{tabular}




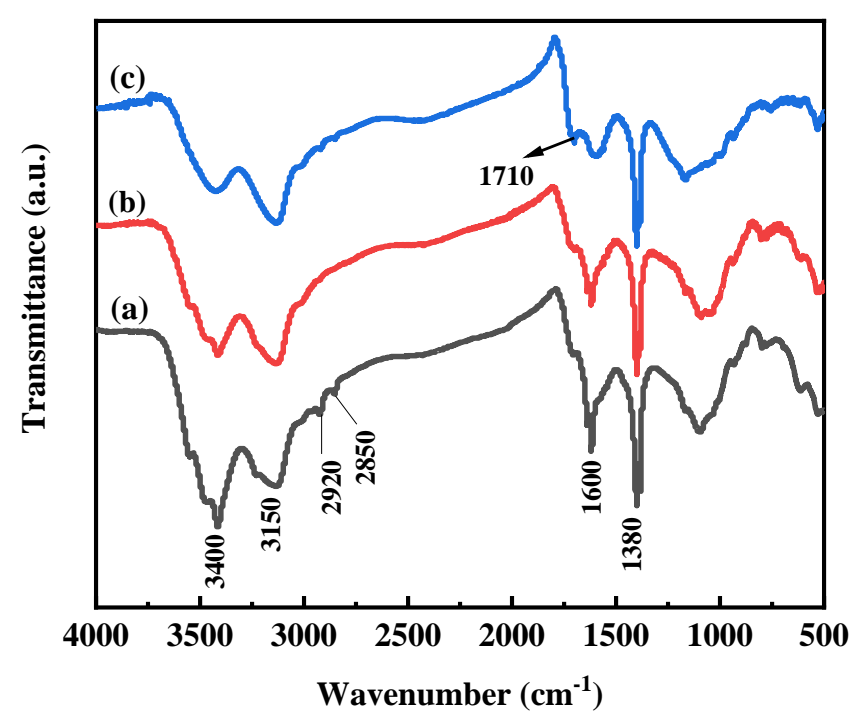

Figure 1. The FTIR spectra of lignite (a), oxygenated lignite (b) and HA(c).

\subsection{Effect of Synthesis Conditions on the Water Absorbency of PAA-KHA}

The impacts of KHA content on the water absorbency of PAA-KHA in deionized water and in $1 \mathrm{wt} \%$ of $\mathrm{NaCl}$ solution are shown in Figure 2. When the KHA content was lower than $6 \mathrm{wt} \%$, it was obvious that water absorbency increased with the increase of KHA content and the peak occurred at $6 \mathrm{wt} \%$. The main reason could be that the number and types of hydrophilic groups on the polymer chain were richer on KHA. The synergistic effect between the groups formed hydrogen bonds with water molecules, which significantly improved the hydrophilicity of the PAA-KHA material and promoted the water absorption behavior. Below the concentration of $6 \mathrm{wt} \%$, the active sites in the system were insufficient and the excess AA could be caused by self-polymerization, and the resulting polymer structure was too dense to form the three-dimensional network structure, which was not conducive to water absorption [35]. However, when the amount of KHA was too high, the water absorption of PAA-KHA was diminished, possibly due to excess KHA which could not interlace into the graft copolymer, resulting in part of the threedimensional network structure of polymer occupied or blocked by the macromolecular KHA, reduced permeability between the inside and outside of the polymer network, and hindered water molecule infiltration [33].

The impacts of APS content on the water absorbency of PAA-KHA in deionized water and in $1 \mathrm{wt} \%$ of $\mathrm{NaCl}$ solution are shown in Figure 3. Both water absorbencies of PAA-KHA reached a peak at $2.1 \mathrm{wt} \%$ of APS. The initiator affects the number of active sites in the reaction system [35]. When the content of APS was lower than $1.5 \mathrm{wt} \%$, there were fewer active sites produced. As a result, the polymerization reaction could not be initiated or the degree of polymerization reaction was much limited. When APS was $1.8 \mathrm{wt} \%$, although the polymerization reaction could be carried out, there were many remaining unreacted monomers in the system. Moreover, the polymer formed had a low molecular weight and a low degree of network crosslinking, leading to its poor absorbing ability of water or $\mathrm{NaCl}$ solution. Then, the water absorbency increases with increasing APS content from 1.8 to $2.1 \mathrm{wt} \%$, the APS provided more active sites, accelerated the grafting reaction between KHA and AA, improved the three-dimensional network structure, and enhanced water absorption [35]. However, when the content of APS was higher than $2.1 \mathrm{wt} \%$, the water absorbency decreased with increase of APS concentration. Because in free-radical chain polymerization using a chemical initiator, the number-average degree of polymerization is inversely proportional to the square root of the concentration of the initiator, the molecular weight of grafting on the polymer backbone would decrease, and the relative amount of polymer chain, which does not contribute to the absorption capacity, ends the increase [36]. Moreover, the excess APS initiator accelerated AA self-polymerization, as indicated by 
shorter chain length in the product, and the resulting polymer was too dense to form the three-dimensional network structure, which was not conducive to water absorption [35].

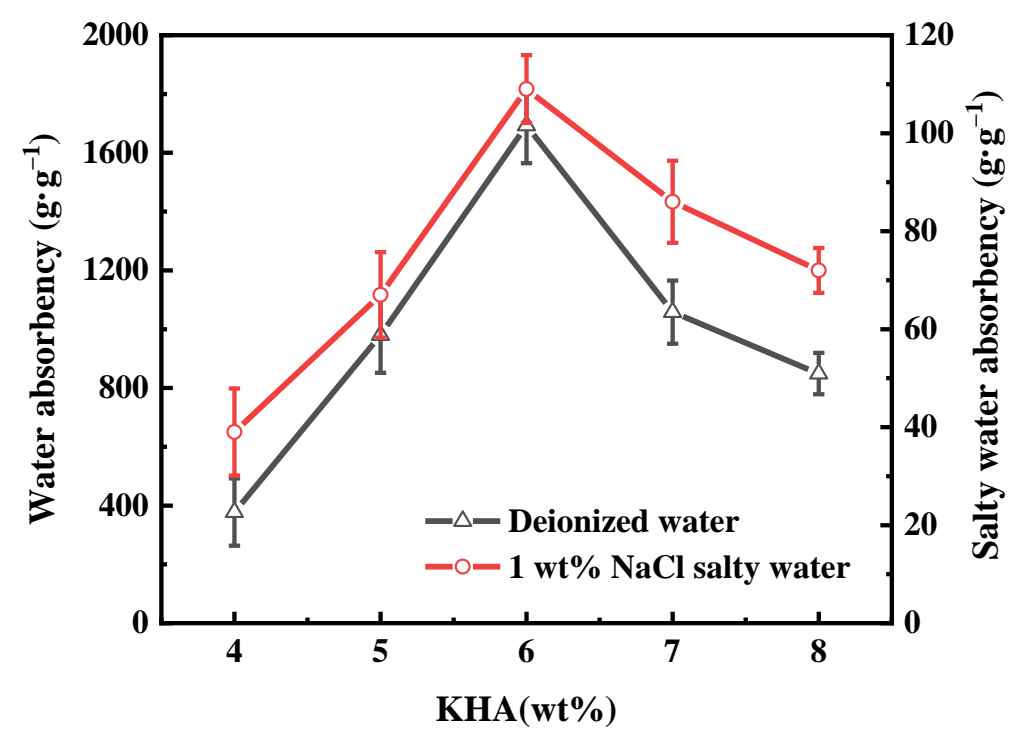

Figure 2. The effect of KHA content on the water absorbency of PAA-KHA in deionized water and in $1 \mathrm{wt} \%$ of $\mathrm{NaCl}$ salty water ( $2 \mathrm{~g}$ of $\mathrm{AA}, 50 \%$ degree of neutralization, $2.1 \mathrm{wt} \%$ of APS and $0.2 \mathrm{wt} \%$ of MBA).

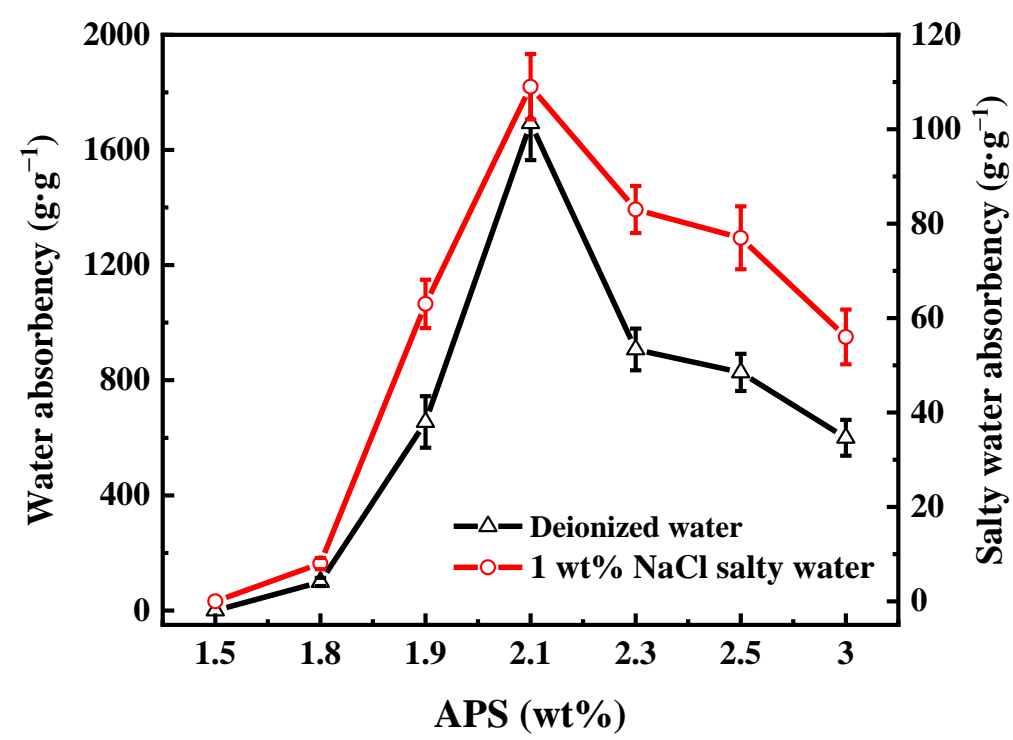

Figure 3. The effect of APS content on the water absorbency of PAA-KHA in deionized water and in $1 \mathrm{wt} \%$ of $\mathrm{NaCl}$ salty water $(2 \mathrm{~g}$ of $\mathrm{AA}, 50 \%$ degree of neutralization, $6 \mathrm{wt} \%$ of $\mathrm{KHA}$ and $0.2 \mathrm{wt} \%$ of MBA).

Different $w \mathrm{t} \%$ of MBA ranging from 0.1 to $0.45 \mathrm{wt} \%$ were used to determine the impacts of the crosslinking agent on PAA-KHA. As shown in Figure 4, with the increase of MBA content, both water absorbency of PAA-KHA in deionized water and in $1 \mathrm{wt} \%$ of $\mathrm{NaCl}$ solution increased first and then decreased. There was a maximum water absorbency when the MBA content was $0.2 \mathrm{wt} \%$, which was $1693 \mathrm{~g} \cdot \mathrm{g}^{-1}$ in deionized water and $109 \mathrm{~g} \cdot \mathrm{g}^{-1}$ in $\mathrm{NaCl}$ solution, respectively. PAA-KHA failed to form a rich crosslinking network structure or strong network structure when the MBA content was relatively low. The low content of MBA made the polymer more water-soluble, and eventually led to a lower absorption ability. Additionally, the decrease of water absorbency when the MBA content exceeded $0.2 \mathrm{wt} \%$ could be attributed to the abundant crosslinking points in the structure. The high 
crosslinking density caused the shrinkage of micropores in the network structure, which limited the relaxation in the water.

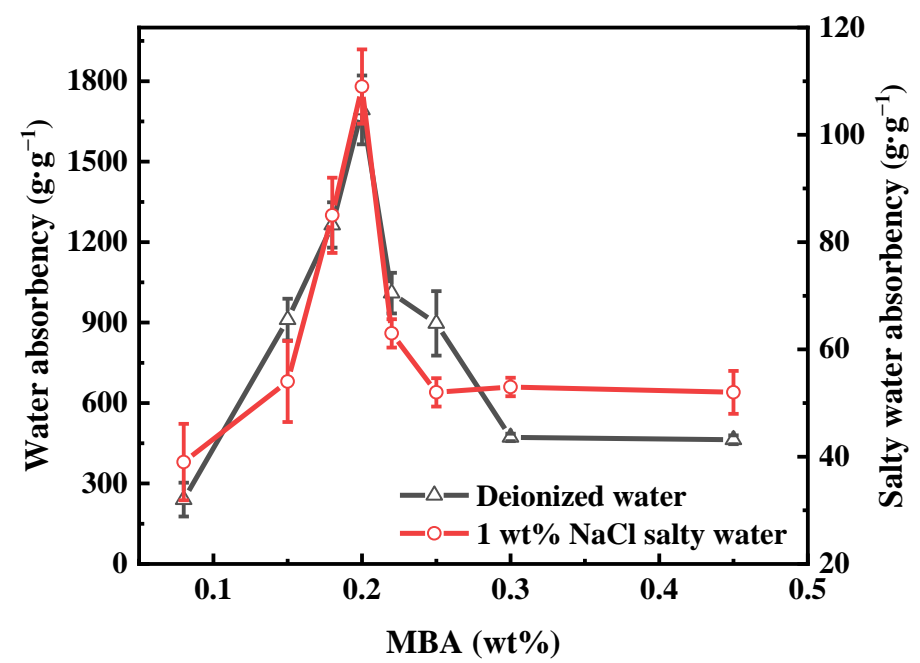

Figure 4. The effect of MBA content on the water absorbency of PAA-KHA in deionized water and in $1 \mathrm{wt} \%$ of $\mathrm{NaCl}$ salty water ( $2 \mathrm{~g}$ of $\mathrm{AA}, 50 \%$ degree of neutralization, $6 \mathrm{wt} \%$ of $\mathrm{KHA}$ and $2.1 \mathrm{wt} \%$ of APS).

The direct addition of AA makes explosive polymerization easier due to the high activity of the AA monomer. Therefore, $\mathrm{KOH}$ was used to neutralize with $-\mathrm{COOH}$ in the AA part. The generated potassium acrylate had a slower polymerization reaction rate and let the reaction proceed more smoothly. Figure 5 shows that the maximum water absorbency of PAA-KHA was found at $50 \%$ degree of neutralization. When the neutralization degree was lower than $50 \mathrm{wt} \%$, the system was more acidic, the reaction was faster, and the crosslinking density of the polymer was higher, which resulted in lower water absorbency. Conversely, the excessive $\mathrm{K}^{+}$ionization in the system made the concentration of $-\mathrm{COO}^{-}$too high when the degree of neutralization was greater than $50 \mathrm{wt} \%$. Therefore, the free motion of polymer chains were limited by mutual repulsion, which limited the expansion of the network microporous structure.

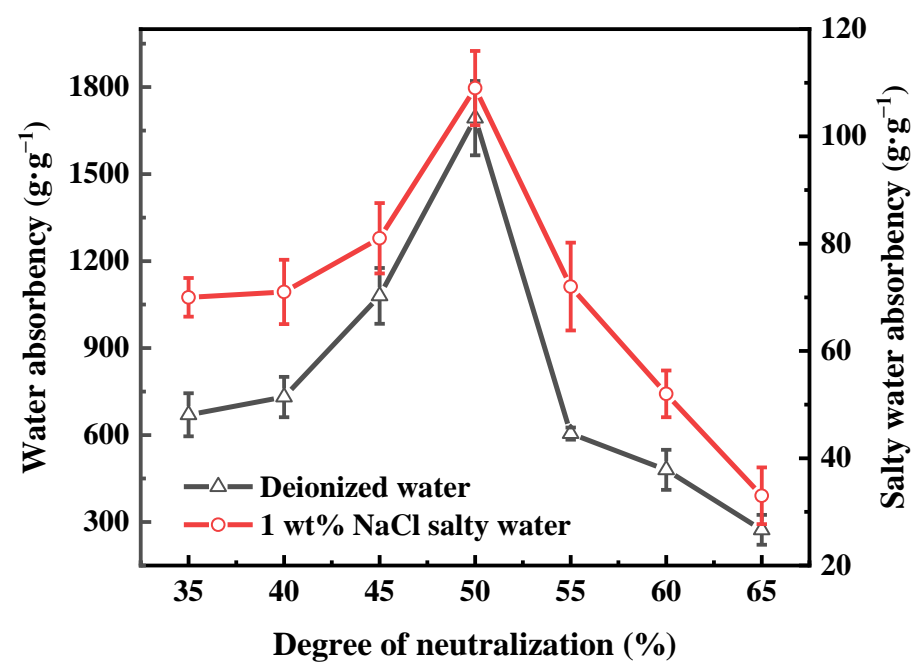

Figure 5. The effect of degree of neutralization on the water absorbency of PAA-KHA in deionized water and in $1 \mathrm{wt} \%$ of $\mathrm{NaCl}$ salty water $(2 \mathrm{~g}$ of $\mathrm{AA}, 6 \mathrm{wt} \%$ of $\mathrm{KHA}, 2.1 \mathrm{wt} \%$ of APS and $0.2 \mathrm{wt} \%$ of MBA). 


\subsection{Properties of PAA-KHA}

The FTIR spectra of PAA-KHA are presented in Figure 6; the broad absorption band of PAA-KHA at 3400,3150 and at $2940 \mathrm{~cm}^{-1}$ appeared due to the stretching vibration of $-\mathrm{OH}$, the $\mathrm{N}-\mathrm{H}$ or $=\mathrm{C}-\mathrm{H}$ of the aromatic ring and stretching vibration of aliphatic $\mathrm{C}-\mathrm{H}$, respectively. The peak occurring at about $2940 \mathrm{~cm}^{-1}$ is attributed to the asymmetric and symmetric aliphatic $\mathrm{C}-\mathrm{H}$ stretching of $\mathrm{CH}_{2}$ groups. The peaks of $1721 \mathrm{~cm}^{-1}$ indicated the stretching vibration of $\mathrm{C}=\mathrm{O}$ originated from $-\mathrm{COOH}$. The adsorption band at $1575 \mathrm{~cm}^{-1}$ in the PAA-KHA spectrum was attributed to the stretching vibration of $\mathrm{C}=\mathrm{C}$ from a large number of extended aromatic rings in potassium humate. Additionally, the sample also exhibited several characteristic signals, such as the $\mathrm{C}-\mathrm{H}$ deformation of $\mathrm{CH}_{2}$ and $\mathrm{CH}_{3}$ groups and/or to antisymmetric stretching of COO- groups at $1380 \mathrm{~cm}^{-1}$, the vibrating absorption of the alkyl aryl at $1286 \mathrm{~cm}^{-1}$, and the vibrating absorption of acrylate -COOat $1161 \mathrm{~cm}^{-1}$ [32]. Due to the interaction between the groups of KHA and PAA, some absorption peaks of PAA-KHA can be observed to become stronger (such as at the peak of 2940, 1721, 1575 and $1286 \mathrm{~cm}^{-1}$ ) or disappear (such as the stretching vibration of aliphatic $\mathrm{C}-\mathrm{H}$ of the $\mathrm{C}=\mathrm{C}$ which originated from the PAA at the peak of $1639 \mathrm{~cm}^{-1}$ ) compared to the PAA indicating that the reaction has taken place. The obtained PAA-KHA polymer also was verified by SEM and EDS in the later section.

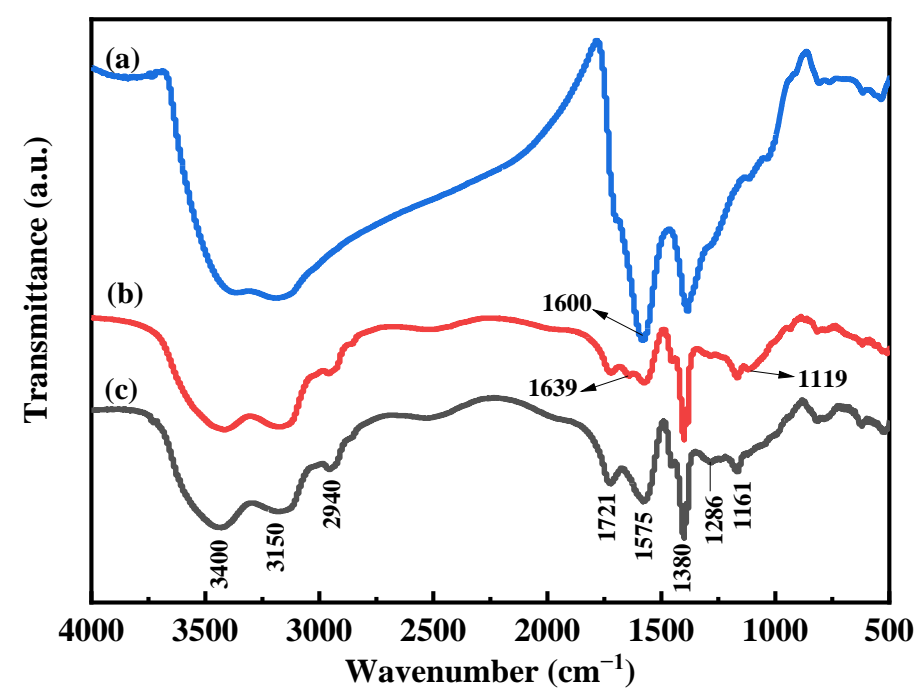

Figure 6. The FTIR spectra of KHA (a), PAA (b) and PAA-KHA (c).

SEM revealed the surface morphologies of PAA-KHA in Figure 7. The surface of PAA-KHA before water absorption was similar to the irregular fish scales in Figure 7a. The PAA-KHA section morphology presented a layered state, in which the upper layer was relatively smooth, and the lower layer presented an orderly vertical pore structure, which provided channels for the water absorption in Figure 7b. EDS analysis of the PAA-KHA material section showed that there were differences in the element composition of the area where each layer was located, as shown in Table 2. It can be inferred from the element content that the first layer was mainly KHA, while the second layer was mainly PAA. The layered structure of the PAA-KHA material was beneficial to the water absorption and water retention of material, while the vertical pores provided channels for water absorption of material. In addition, the interpenetrating network structure in the KHA layer acted as a micro reservoir, which provided a water storage container for water storage after the material absorbs water. The SEM of freeze-dried PAA-KHA after absorption water and saturation is shown in Figure 7c,d, the PAA-KHA was freeze-dried after water absorption saturation and the corresponding PAA layer and KHA layer pore channels were opened. Due to the rich pore structure, the PAA-KHA as the coating material of fertilizer can maintain a good water absorption and retention effect. 

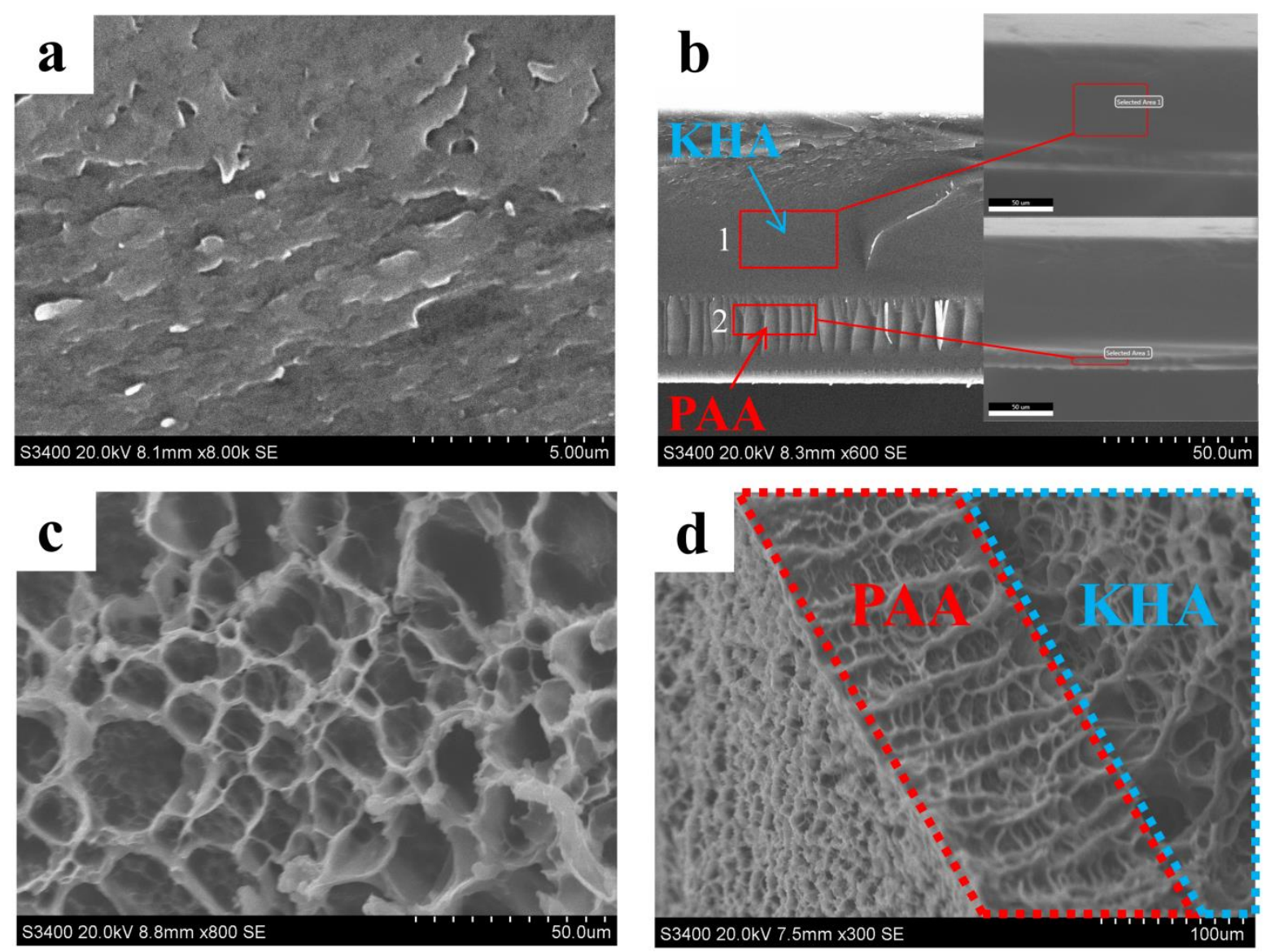

Figure 7. SEM images of PAA-KHA: (a) surface before water absorption, (b) section before water absorption, (c) surface after water absorption, and (d) section after water absorption.

Table 2. Element composition of different areas of PAA-KHA.

\begin{tabular}{ccccccc}
\hline \multirow{2}{*}{ Regions } & \multicolumn{3}{c}{ Element Mass Percent (wt\%) } & \multicolumn{3}{c}{ Atom Percent (at\%) } \\
& $\mathbf{C}$ & $\mathbf{O}$ & $\mathbf{K}$ & $\mathbf{C}$ & $\mathbf{O}$ & K \\
\hline The first layer & 31.91 & 40.73 & 27.35 & 45.01 & 43.13 & 11.85 \\
The second layer & 39.57 & 39.60 & 20.83 & 52.28 & 39.27 & 8.45 \\
\hline
\end{tabular}

Figure 8 shows the curve of the water absorbency of PAA and PAA-KHA in deionized water and in $1 \mathrm{wt} \%$ of $\mathrm{NaCl}$ solution, respectively. The water absorbency of PAA-KHA increased with time increment in an " $\mathrm{S}$ " shape and the water absorbency reached the saturation state in about $230 \mathrm{~min}$ and $200 \mathrm{~min}$, respectively. The water absorption process consists of three stages: In the first stage, the water absorbency is slow because the water molecules entered the porous interpenetrating network structure and made full contact with it when PAA-KHA was in contact with water, so that the interaction between ions was small at the time. In the second stage, the water absorbency improved due to the strong hydration between hydrophilic groups and water molecules when PAA-KHA began to absorb water, and the ion concentration of the solution in the porous interpenetrating network structure was very high, resulting in a large osmotic pressure difference between the inside and outside of the solution. In the third stage, the water absorbency slowed down again as the ion concentration of the solution decreased and the osmotic pressure difference between the inside and outside decreased after a large amount of water molecules entering the PAA-KHA structure. Finally, the water absorbency slows down to saturation because of the binding effect of the polymer chain. In addition, the water absorbency of PAA-KHA was much higher than that of PAA whether it was in deionized water or salt solution, while the time required to reach the absorption saturation of PAA-KHA was shorter than 
that of PAA, which proved that PAA-KHA had better and faster water absorption capacity. The PAA-KHA material coated fertilizer may reduce the irrigation time and frequency in agriculture.
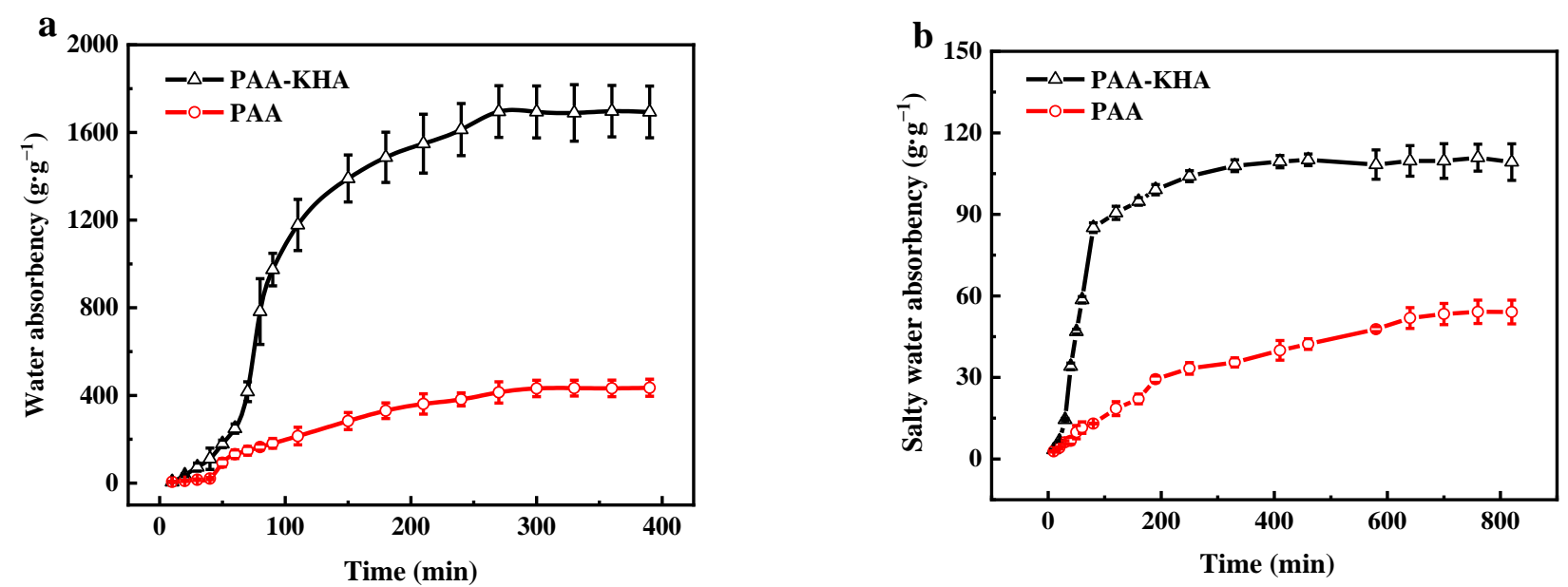

Figure 8. Water absorbency of PAA ( $2 \mathrm{~g}$ of AA, $2.1 \mathrm{wt} \%$ of APS and $0.2 \mathrm{wt} \%$ of MBA) and PAA-KHA ( $2 \mathrm{~g}$ of AA, $6 \mathrm{wt} \%$ of KHA, $2.1 \mathrm{wt} \%$ of APS and $0.2 \mathrm{wt} \%$ of MBA) in deionized water (a) and in $1 \mathrm{wt} \%$ of $\mathrm{NaCl}$ salty water (b), respectively.

As seen in Figure 9, the water absorbency of PAA and PAA-KHA decreased with the increase of $\mathrm{NaCl}$ solution concentration from 1 to $10 \mathrm{wt} \%$, respectively. The reason was that after the PAA and PAA-KHA absorbed salty water they were in a gel state, the ion concentration in the solution increased, so that the shielding effect between ions increased and the osmotic pressure difference between inside and outside the pore structure decreased, which limited the expansion of their network structure and led to the decrease of water absorbency. In the same concentration of $\mathrm{NaCl}$ solution, the water absorbency of PAA-KHA was about 3 times higher than that of PAA. For example, the water absorbency of PAA-KHA was $61.3 \mathrm{~g} \cdot \mathrm{g}^{-1}$ when the concentration of $\mathrm{NaCl}$ salty water was $4 \mathrm{wt} \%$, while PAA was only $22.5 \mathrm{~g} \cdot \mathrm{g}^{-1}$. These results demonstrated that the addition of HA significantly improved the salt resistance of the coating material regardless of the concentration of salt solution.

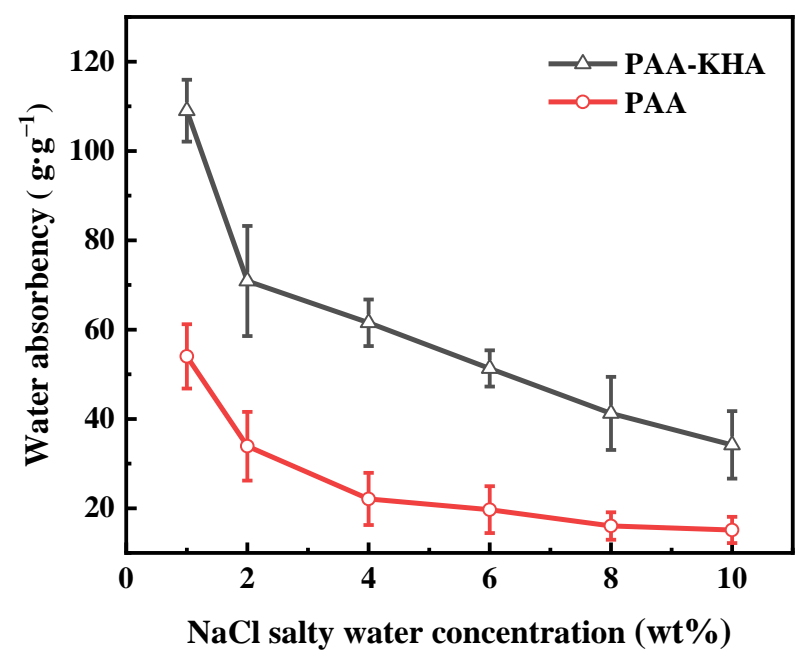

Figure 9. The effect of $\mathrm{NaCl}$ salty water concentration on water absorbency of PAA and PAA-KHA.

The repeated water absorbency of the PAA and PAA-KHA are shown in Figure 10, respectively. The water absorbency of PAA and PAA-KHA decreased with the increase of water absorption frequency. Compared with PAA, the decreased rate of PAA-KHA 
was relatively faster. The water absorbency of PAA-KHA after the fifth repetition was $114 \mathrm{~g} \cdot \mathrm{g}^{-1}$, only $6.73 \%$ of the water absorbency of the first time, while that of PAA was $62.5 \%$ of the water absorbency of the first time. This phenomenon may be caused by the partial destruction of PAA-KHA structure during the repeated water absorption process. The PAA-KHA weight is only $28 \%$ of the original sample after the fifth repetition of water drying, which proved that part of the polymer may be partially dissolved in water, and indirectly indicates that PAA-KHA, as a fertilizer coating material, has degradability in the soil environment. Figure 11 shows that both PAA and PAA-KHA water retention rates presented a downward trend with time, and the steepness of PAA-KHA was slower than PAA. PAA lost almost all of its water by the third day, while PAA-KHA still had $5 \%$ of water content after six days. It proved that the introduction of KHA not only increased the hydrophilic group of the material, but also introduced the internal multi-pore interpenetrating network structure of the PAA-KHA, shown in Figure 7. This structure enabled PAA-KHA to have a larger contact area with water molecules, thus enhancing the hydrophilicity and water retention performance of PAA-KHA.

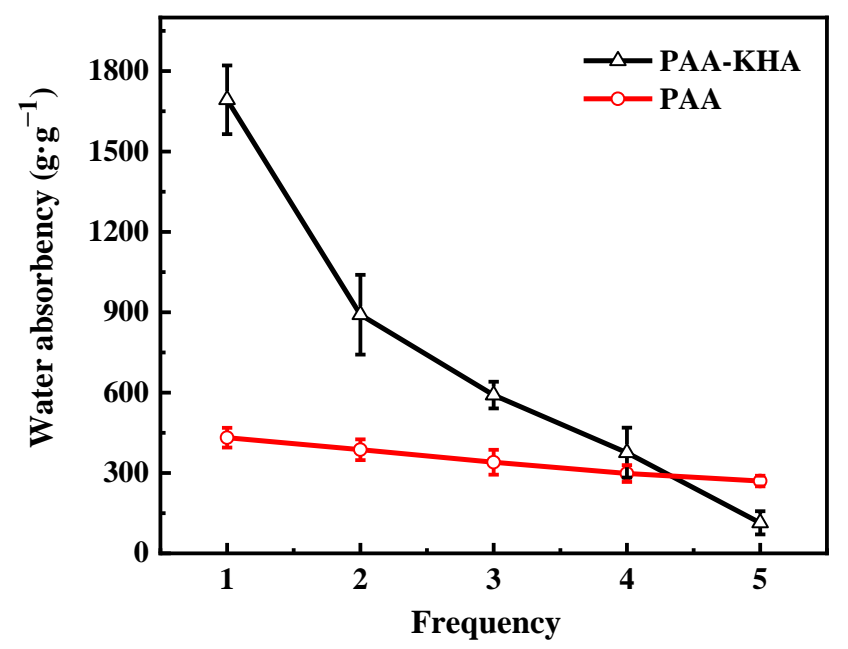

Figure 10. The repeated water absorbency of PAA and PAA-KHA.

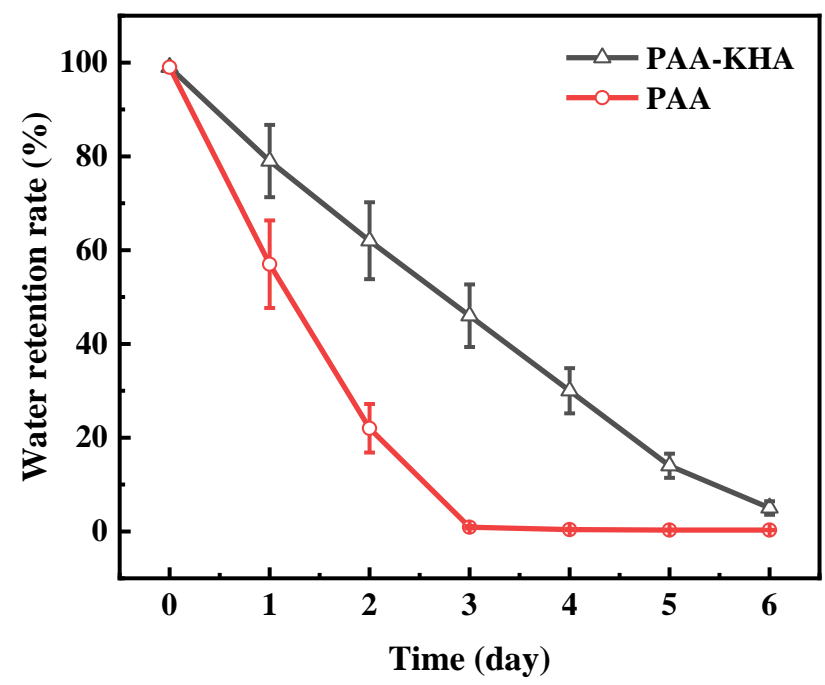

Figure 11. Water retention of PAA and PAA-KHA.

\subsection{Properties of ADP@PAA-KHA Fertilizer}

ADP@PAA-KHA sample with coating rate of $10 \%$ was selected, and its slow-release performance for $24 \mathrm{~h}$ and 15 days are shown in Figure 12, respectively. 


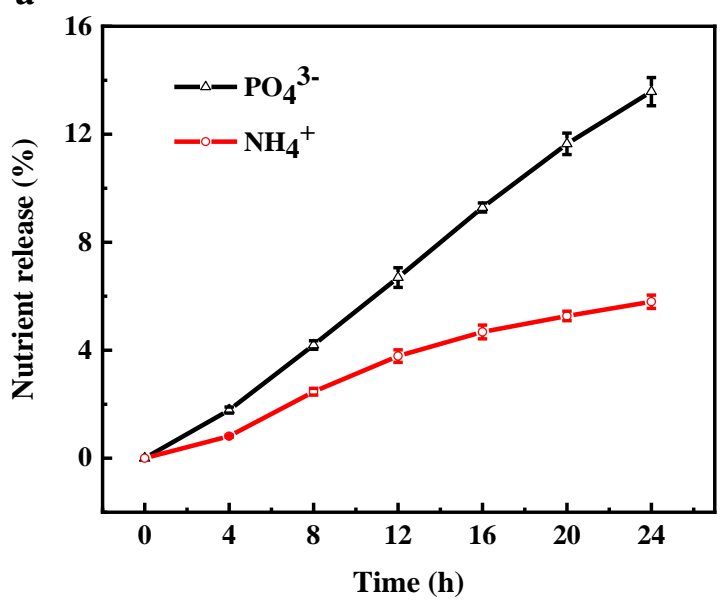

b

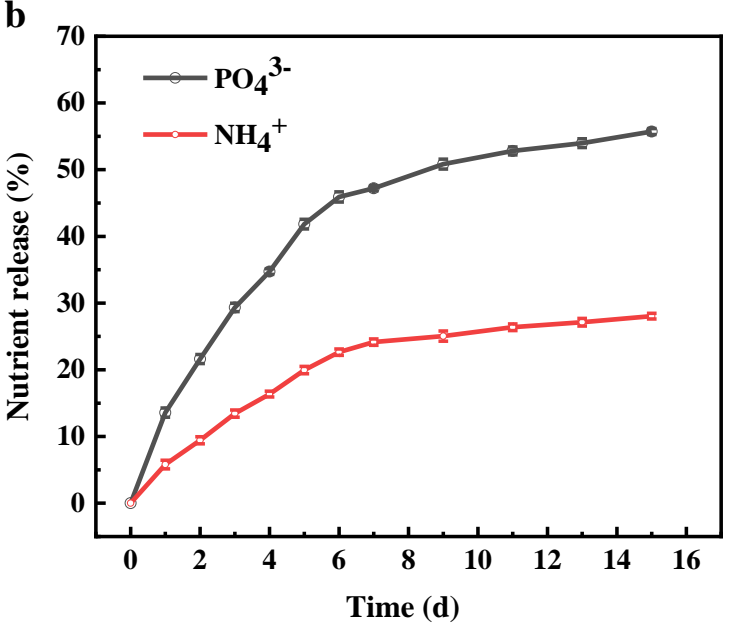

Figure 12. The cumulative release rate of ADP@PAA-KHA at different times, (a) $24 \mathrm{~h}$, and (b) 15 days.

In Figure 12, the release rate of $\mathrm{PO}_{4}{ }^{3-}$ was much higher than that of $\mathrm{NH}_{4}{ }^{+}$in static water. The cumulative release rate of nutrients in the ADP@PAA-KHA after $24 \mathrm{~h}$ was lower than $20 \%$. The release of nutrients was very slow in the initial $4 \mathrm{~h}$, because the pore structure network of PAA-KHA was not sufficiently open in the early stage; it can be seen from the morphology of the ADP@PAA-KHA absorbed water for 20 min in Figure 13c, while the interpenetrating network structure of PAA-KHA has not yet opened by the intake of water. The nutrients were slowly released and dissolved in the aqueous solution when the network structure was filled with water after $4 \mathrm{~h}$. According to Figure 12b, the releasing rates of $\mathrm{PO}_{4}{ }^{3-}$ and $\mathrm{NH}_{4}{ }^{+}$were relatively fast in the first 6 days. This was because the three-dimensional interpenetrating network structure was fully opened after the PAA-KHA material absorbed adequate water and the concentration gradient of internal and external was large, which finally accelerated the nutrients release rate. As shown in Figures $7 \mathrm{~d}$ and $13 \mathrm{~d}$, the pore structure of PAA-KHA was completely opened after water absorption and saturation. The cumulative release of $\mathrm{PO}_{4}{ }^{3-}$ and $\mathrm{NH}_{4}{ }^{+}$were $45.92 \%$ and $22.65 \%$ on first 6 days, respectively. The cumulative release rates of $\mathrm{PO}_{4}{ }^{3-}$ and $\mathrm{NH}_{4}{ }^{+}$ were $55.71 \%$ and $28.04 \%$ after the 15th day, respectively. It can be seen that the nutrients release rate slows down obviously, which indicated that the fertilizer had good slowrelease characteristics.

The morphologies and water absorption performance of ADP@PAA-KHA are shown in Figure 13. The surface of the coated fertilizer (Figure 13b) became smoother after being embedded by PAA-KHA than the surface before coating (Figure 13a). After the ADP@PAAKHA absorbed water for $20 \mathrm{~min}$, the interpenetrating network structure of PAA-KHA had not yet opened by swelling in process of contacting with water, and the surface with sufficient contact with water showed a burr shape due to water absorption (Figure 13c). However, the water completely entered the interpenetrating network structure, which formed a miniature reservoir (Figure 13d) after $24 \mathrm{~h}$. The weight change of ADP@PAA-KHA with a $10 \%$ coating rate before and after absorbing water in deionized water was about 53 times, and it was about 4 times in $1 \mathrm{wt} \%$ of $\mathrm{NaCl}$ salty water. The results showed that the ADP@PAA-KHA had prominent performance on water retention and salt tolerance. 

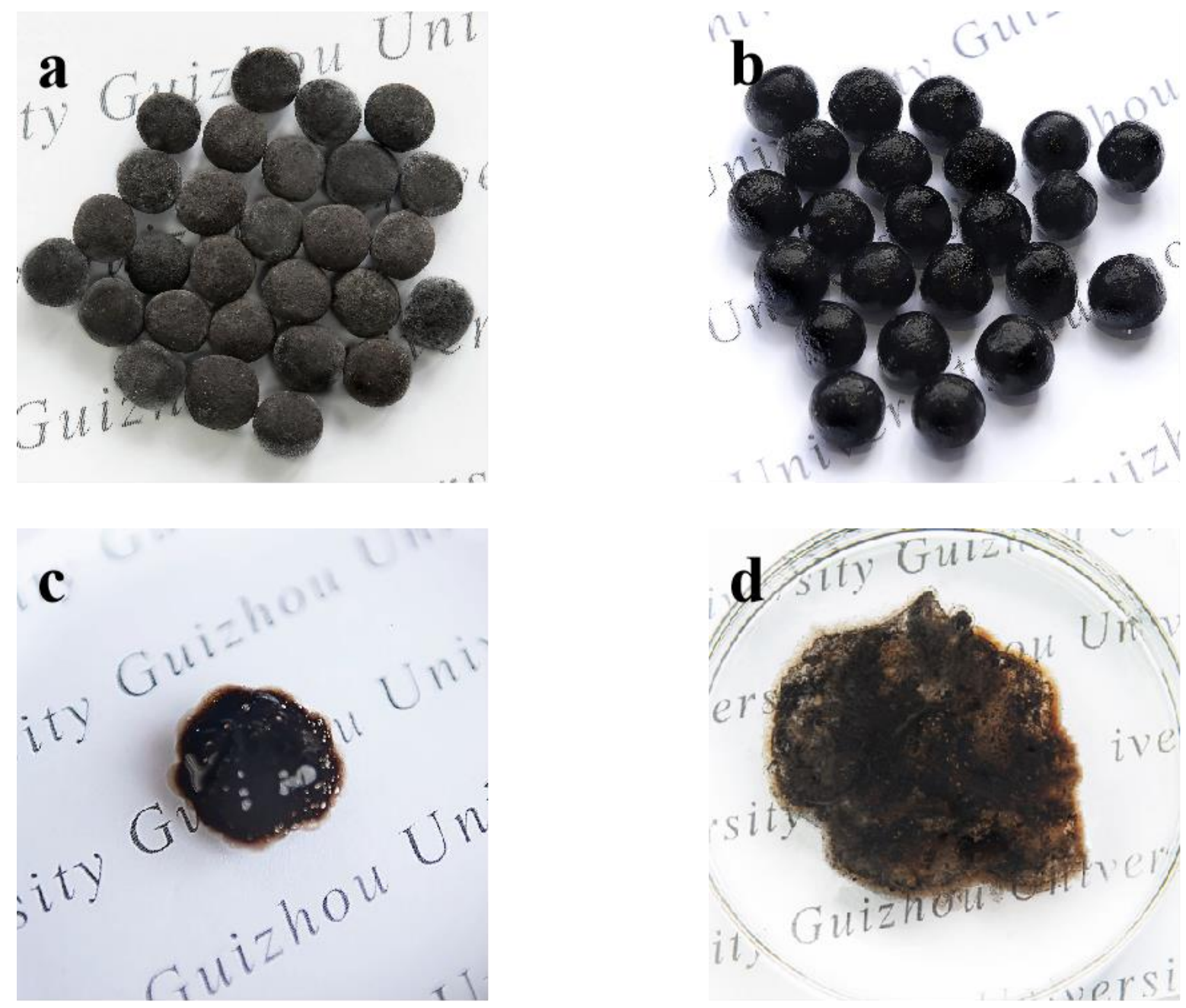

Figure 13. Electronic digital photograph of fertilizer: (a) fertilizer core, (b) ADP@PAA-KHA, (c) ADP@PAA-KHA absorbs water for $20 \mathrm{~min}$, and (d) ADP@PAA-KHA absorbs water for $24 \mathrm{~h}$.

\section{Conclusions}

The study selected lignite as the source, $\mathrm{H}_{2} \mathrm{O}_{2}$ as the oxidant to oxygenize lignite and then HA was extracted from lignite. Then the HA and AA monomers were used to prepare a coating material of PAA-KHA by aqueous solution polymerization. The optimum preparation conditions were $50 \%$ degree of neutralization of $2 \mathrm{~g}$ of AA with a composition of $6 \mathrm{wt} \%$ of KHA, $2.1 \mathrm{wt} \%$ of APS and $0.2 \mathrm{wt} \%$ of MBA. PAA-KHA had a layered interpenetrating network, which can provide sufficient storage space for water and nutrients. The water absorbency of PAA-KHA was as high as $1693 \mathrm{~g} \cdot \mathrm{g}^{-1}$ and $109 \mathrm{~g} \cdot \mathrm{g}^{-1}$ in deionized water and $1 \mathrm{wt} \%$ of $\mathrm{NaCl}$ salty water solution. The salt resistance of PAA-KHA increased by about 3 times that of PAA. The water absorbency remained at $114 \mathrm{~g} \cdot \mathrm{g}^{-1}$ after 5 re-absorptions. There was still 5\% of water content after 6 days exposure in the air at $35{ }^{\circ} \mathrm{C}$. Both the $\mathrm{PO}_{4}{ }^{3-}$ and $\mathrm{NH}_{4}{ }^{+}$cumulative release of ADP@PAA-KHA with coating rate of $10 \%$ in deionized water, were less than $20 \%$ within $24 \mathrm{~h}$. The cumulative release rates of $\mathrm{PO}_{4}{ }^{3-}$ and $\mathrm{NH}_{4}{ }^{+}$were $55.71 \%$ and $28.04 \%$ within 15 days, respectively. The weight change of ADP@PAA-KHA before and after absorbing water was about 53 times in deionized water and about 4 times in $1 \mathrm{wt} \%$ of $\mathrm{NaCl}$ salty solution. The ADP@PAA-KHA has excellent properties of water retention, salt-resistance and slow-release, and it could efficiently improve the utilization of fertilizer and reduce the irrigation water consumption at the same time. 
Author Contributions: Conceptualization, G.X.; methodology, G.X. and H.L. (Hongping Li); formal analysis, G.X., H.L. (Hongping Li), C.N. and J.C.; investigation, G.X., H.L. (Hongping Li), L.Y., H.L. (Hao Liu) and P.G.; writing-original draft preparation, G.X., H.L. (Hongping Li) and L.Y.; writing-review and editing, G.X.; project administration, G.X. and J.C.; funding acquisition, J.C., J.T. and W.C. All authors have read and agreed to the published version of the manuscript.

Funding: This work was supported by the Guizhou Science and Technology Department (China) (grant number [2019]1093) and the Science \& Technology Plan Projects of Guizhou Province (Qiankehe platform talent [2017] 5711) and (Contract No.: Qianke Hefu Enterprise [2018]4011) and Guizhou Provincial Education Department (China) (Contract No.: Qianjiaohe [2021]091) and State Key Laboratory of Efficient Utilization for Low Grade Phosphate Rock and Its Associated Resources (WFKF2019-04) and National College Student Innovation and Entrepreneurship Training Program (2018016).

Institutional Review Board Statement: Not applicable.

Informed Consent Statement: Not applicable.

Data Availability Statement: The data used to support the findings of this study are included within the article.

Conflicts of Interest: The authors declare no conflict of interest.

\section{Nomenclature}

\begin{tabular}{|c|c|}
\hline PAA & Polyacrylic acid \\
\hline HA & Humic acid \\
\hline KHA & Potassium humate \\
\hline PAA-KHA & Polyacrylic acid-potassium humate \\
\hline $\mathrm{ADP}$ & Ammonium dihydrogen phosphate \\
\hline ADP@PAA-KHA & $\begin{array}{l}\text { Polyacrylic acid-potassium humate coated ammonium } \\
\text { dihydrogen phosphate fertilizer }\end{array}$ \\
\hline AA & Acrylic acid \\
\hline APS & Ammonium persulfate \\
\hline MBA & $\mathrm{N}, \mathrm{N}^{\prime}$-methylene amide \\
\hline $\mathrm{w}$ & coated rate $(\%)$ \\
\hline $\mathrm{m}_{1}$ & the weight of fertilizer cores (g) \\
\hline $\mathrm{m}_{2}$ & the weight of ADP@PAA-KHA (g) \\
\hline $\mathrm{H}$ & water absorbency $\left(\mathrm{g} \cdot \mathrm{g}^{-1}\right)$ \\
\hline $\mathrm{M}_{1}$ & the mass of PAA-KHA (g) \\
\hline $\mathrm{M}_{2}$ & the mass of PAA-KHA after fully swelling in deionized or salty water $(\mathrm{g})$ \\
\hline W & the cumulative release rate of each nutrient $(\%)$ \\
\hline $\mathrm{V}_{\mathrm{E}}$ & the volume of sample solution (L) \\
\hline $\mathrm{V}_{0}$ & the volume of solution in the container $(\mathrm{L})$ \\
\hline $\mathrm{C}_{\mathrm{i}}$ & the concentration of nutrient in the sample solution $\left(\mathrm{mg} \cdot \mathrm{L}^{-1}\right)$ \\
\hline $\mathrm{C}_{\mathrm{n}}$ & the concentration of the solution in the container $\left(\mathrm{mg} \cdot \mathrm{L}^{-1}\right)$ \\
\hline $\mathrm{n}$ and $\mathrm{i}$ & the number of samples \\
\hline$m_{x}$ & the nutrient mass in the sample $(\mathrm{mg})$ \\
\hline
\end{tabular}

\section{References}

1. Azeem, B.; KuShaari, K.; Man, Z.B.; Basit, A.; Thanh, T.H. Review on materials \& methods to produce controlled release coated urea fertilizer. J. Control. Release 2014, 181, 11-21.

2. Xu, Y.; Wang, J.; Gu, T.; Kong, J.; Moayedi, H. Geological Hazards in Loess Induced by Agricultural Irrigation in Arid and Semiarid Regions of China. Adv. Civil. Eng. 2020, 2020,1-11.

3. Fu, J.; Wang, C.; Chen, X.; Huang, Z.; Chen, D. Classification research and types of slow controlled release fertilizers (SRFs) used-A review. Commun. Soil Sci. Plant Anal. 2018, 49, 2219-2230. [CrossRef]

4. Li, T.; Lü, S.; Zhang, S.; Gao, C.; Liu, M. Lignin-based multifunctional fertilizer for immobilization of Pb (II) in contaminated soil. J. Taiwan Inst. Chem. Eng. 2018, 91, 643-652. [CrossRef]

5. Beerthuis, R.; Rothenberg, G.; Shiju, N.R. Catalytic routes towards acrylic acid, adipic acid and $\varepsilon$-caprolactam starting from biorenewables. Green Chem. 2015, 17, 1341-1361. [CrossRef] 
6. Du, W.; Slany, M.; Wang, X.; Chen, G.; Zhang, J. The Inhibition Property and Mechanism of a Novel Low Molecular Weight Zwitterionic Copolymer for Improving Wellbore Stability. Polymers 2020, 12, 708. [CrossRef]

7. Zohuriaan-Mehr, M.J.; Kabiri, K. Superabsorbent Polymer Materials: A Review. Iran. Polym. J. 2008, 17, $451-477$.

8. Chang, L.; Xu, L.; Liu, Y.; Qiu, D. Superabsorbent polymers used for agricultural water retention. Polym. Test. $2021,94,107021$. [CrossRef]

9. Zhang, J.; Liu, R.; Li, A.; Wang, A. Preparation, Swelling Behaviors, and Slow-Release Properties of a Poly(acrylic acid-coacrylamide)/Sodium Humate Superabsorbent Composite. Ind. Eng. Chem. Res. 2006, 45, 48-53. [CrossRef]

10. Zaini, M.A.; Amano, Y.; Machida, M. Adsorption of heavy metals onto activated carbons derived from polyacrylonitrile fiber. J. Hazard. Mater. 2010, 180, 552-560. [CrossRef]

11. Chai, W.; Huang, Y.; Han, G.; Liu, J.; Yang, S.; Cao, Y. An Enhanced Study on Adsorption of Al(iii) onto Bentonite and Kaolin: Kinetics, Isotherms, and Mechanisms. J. Min. Proc. Ext. Met. Rev. 2016, 38, 106-115. [CrossRef]

12. Karlsson, R.P.; Larsson, P.T.; Hansson, P.; Wagberg, L. Thermodynamics of the Water-Retaining Properties of Cellulose-Based Networks. Biomacromolecules 2019, 20, 1603-1612. [CrossRef] [PubMed]

13. Cui, Y.; Xiang, Y.; Xu, Y.; Wei, J.; Zhang, Z.; Li, L.; Li, J. Poly-acrylic acid grafted natural rubber for multi-coated slow release compound fertilizer: Preparation, properties and slow-release characteristics. Int. J. Biol. Macromol. 2020, 146, 540-548. [CrossRef] [PubMed]

14. Zhao, C.; Zhang, M.; Liu, Z.; Guo, Y.; Zhang, Q. Salt-Tolerant Superabsorbent Polymer with High Capacity of Water-Nutrient Retention Derived from Sulfamic Acid-Modified Starch. ACS Omega 2019, 4, 5923-5930. [CrossRef] [PubMed]

15. Guo, M.; Liu, M.; Zhan, F.; Wu, L. Preparation and properties of a slow-release membrane-encapsulated urea fertilizer with superabsorbent and moisture preservation. Ind. Eng. Chem. Res. 2005, 44, 4206-4211. [CrossRef]

16. Fang, S.; Wang, G.; Xing, R.; Chen, X.; Liu, S.; Qin, Y.; Li, K.; Wang, X.; Li, R.; Li, P. Synthesis of superabsorbent polymers based on chitosan derivative graft acrylic acid-co-acrylamide and its property testing. Int. J. Biol. Macromol. 2019, 132, 575-584. [CrossRef]

17. Chen, J.; Lu, S.; Zhang, Z.; Zhao, X.; Li, X.; Ning, P.; Liu, M. Environmentally friendly fertilizers: A review of materials used and their effects on the environment. Sci. Total Environ. 2018, 613-614, 829-839. [CrossRef]

18. Meng, Y.; Ye, L. Synthesis and swelling property of superabsorbent starch grafted with acrylic acid/2-acrylamido-2-methyl-1propanesulfonic acid. J. Sci. Food Agric. 2017, 97, 3831-3840. [CrossRef]

19. Olad, A.; Doustdar, F.; Gharekhani, H. Starch-based semi-IPN hydrogel nanocomposite integrated with clinoptilolite: Preparation and swelling kinetic study. Carbohydr. Polym. 2018, 200, 516-528. [CrossRef]

20. Motamedi, E.; Motesharezedeh, B.; Shirinfekr, A.; Samar, S.M. Synthesis and swelling behavior of environmentally friendly starchbased superabsorbent hydrogels reinforced with natural char nano/micro particles. J. Environ. Chem. Eng. 2020, 8, 103583. [CrossRef]

21. Xu, S.; Yin, Y.; Wang, Y.; Li, X.; Hu, Z.; Wang, R. Amphoteric superabsorbent polymer based on waste collagen as loading media and safer release systems for herbicide 2, 4-D. J. Appl. Polym. Sci. 2019, 137, 48480. [CrossRef]

22. Zhang, S.; Yuan, L.; Li, W.; Lin, Z.; Li, Y.; Hu, S.; Zhao, B. Effects of urea enhanced with different weathered coal-derived humic acid components on maize yield and fate of fertilizer nitrogen. J. Integr. Agric. 2019, 18, 656-666. [CrossRef]

23. Li, Y. Research Progress of Humic Acid Fertilizer on the Soil. J. Phys. Conf. Ser. 2020, 1549, 022004. [CrossRef]

24. Radwan, E.K.; Ibrahim, M.B.M.; Moursy, A.S.; Ghafar, H.H.A. Characterization of Humic Acids Extracted From Egyptian Sediment by Elemental Composition, NMR and FTIR. J. Environ. Sci. Technol. 2019, 12, 221-227. [CrossRef]

25. Huang, H.-L.; Huang, H.-H.; Wei, Y.J. Reduction of toxic Cr(VI)-humic acid in an ionic liquid. Spectrochim. Acta Part B At. Spectrosc. 2017, 133, 9-13. [CrossRef]

26. Yong, S.L.; Bartlett, R.J. Stimulation of Plant Growth by Humic Substances. Soil Sci. Soc. Am. J. 1976, 40, 876-879.

27. Shen, Y.; Jiao, S.; Ma, Z.; Lin, H.; Gao, W.; Chen, J. Humic acid-modified bentonite composite material enhances urea-nitrogen use efficiency. Chemosphere 2020, 255, 126976. [CrossRef] [PubMed]

28. Zhou, X. Preparation and Properties of Chitosan-g-Poly(acrylic acid)/humic Acid and Water-Retaining Slow-Release Fertilizer. Master's Thesis, Guizhou University, Guizhou, China, 2016.

29. Zhou, L.; Slany, M.; Bai, B.; Du, W.; Qu, C.; Zhang, J.; Tang, Y. Enhanced Removal of Sulfonated Lignite from Oil Wastewater with Multidimensional MgAl-LDH Nanoparticles. Nanomaterials 2021, 11, 861. [CrossRef]

30. Cui, X.; Yang, M.; Zhang, X.; Gao, H.; Wang, G. Introduction to the Analysis Methods of Oxygen Functional Groups in Coal. J. Chem. 2012, 75, 808-814.

31. Wang, W.; Yang, Z.; Zhang, A.; Yang, S. Water retention and fertilizer slow release integrated superabsorbent synthesized from millet straw and applied in agriculture. Ind. Crop. Prod. 2021, 160, 113126. [CrossRef]

32. Slaný, M.; Jankovič, L'.; Madejová, J. Structural characterization of organo-montmorillonites prepared from a series of primary alkylamines salts: Mid-IR and near-IR study. Appl. Clay Sci. 2019, 176, 11-20. [CrossRef]

33. Wu, J.; Wei, Y.; Lin, J.; Lin, S. Study on starch-graft-acrylamide/mineral powder superabsorbent composite. Polymer 2003, 44, 6513-6520. [CrossRef]

34. Wu, M.; Song, M.; Liu, M.; Jiang, C.; Li, Z. Fungicidal activities of soil humic/fulvic acids as related to their chemical structures in greenhouse vegetable fields with cultivation chronosequence. J. Sci. Rep. 2016, 6, 32858. [CrossRef]

35. Wang, W.; Yang, S.; Zhang, A.; Yang, Z. Synthesis of a slow-release fertilizer composite derived from waste straw that improves water retention and agricultural yield. Sci. Total Environ. 2021, 768, 144978. [CrossRef] [PubMed]

36. Liu, Z.S.; Rempel, G.L. Preparation of superabsorbent polymers by crosslinking acrylic acid and acrylamide copolymers. J. Appl. Polym. Sci. 2015, 64, 1345-1353. [CrossRef] 